\title{
PHARMACEUTICAL QUALITY MANAGEMENT SYSTEM: A REVIEW
}

\author{
Available online at www.ijdra.com \\ REVIEW ARTICLE \\ Sharma S*, Bodla R.B., Shweta S, Pathak D.P. \\ Delhi Institute of Pharmaceutical Sciences and Research, New Delhi, India \\ *Corresponding Author's E-mail: sharmashrey7@gmail.com
}

\begin{abstract}
ICH is "International Conference on Harmonization" of technical requirements for registration of pharmaceuticals for human use. The goal of ICH is to discuss and establish common guidelines by bringing together three ICH regions i.e. USA, Japan and EU and to make information available on $\mathrm{ICH}$, its activities and guidelines. The guidelines have become more relevant for Generic's Drug Approval. Drug Development and manufactures are more and more global. Harmonization is considered more important than ever, as it facilitates work sharing, efficient use of resources and access to medicines. The objective of harmonization is meant for economical use of human, animal and other resources and the elimination of unnecessary delay in the global development and of availability of new medicines whilst maintaining safeguards on quality, safety and efficacy.

The present discussion of the review is on ICH guidelines for quality control focussing mainly on Quality Risk Management (Q9). Quality control is a process that is used to ensure a certain level of quality in a product or service. It might include whatever action a business deems necessary to provide for the control and verification of certain characteristics of a product or service. Most often, it involves thoroughly examining and testing the quality of products or the results of services. The basic goal of this process is to ensure that the products or services that are provided meet specific requirements and characteristics, such as being dependable, satisfactory, safe and fiscally sound.
\end{abstract}

Quality risk management is a systematic process for the assessment, control, communication and review of risks to the quality of the drug product across the product lifecycle. Two primary principles of quality risk management are:

- The evaluation of the risk to quality should be based on scientific knowledge and

Ultimately linked to the protection of the patient; and

- The level of effort, formality, and documentation of the quality risk management process should be commensurate with the level of risk.

Keywords: Quality Risk Management (Q9), ICH, Quality risk management.

\section{INTRODUCTION}

$\mathrm{ICH}$ is a joint initiative involving both Regulators and Research-based industry initiatives of the Europe, Japan and US for the scientific and technical discussions of the testing procedures; required to assess and ensure the Safety, Quality and Efficacy of the medicines.

ICH Stands for "International Conference on Harmonization" of Technical Requirements for Registration of Pharmaceuticals for Human use. (1)

Aim

ICH was established in 1990, as a joint regulatory/ industry project to improve, through harmonization, the efficiency of the process, for developing and registering new medicinal products in Europe, Japan and US.

To make medicinal products available to the patients with minimum of a delay. (1)

\section{Need of ICH}

At the time, the Pharma market had become increasingly international and Industry was seeking to market its products internationally.

The 3 major Pharma market were USA, Europe and Japan- the "Triad". While all three had Drug Regulatory approval systems and that too were based on same principles. This means-The detailed technical requirements in each region differed. (1)

For the Industry, this meant: 


\section{Duplicate test procedures.}

Duplicate test procedures were time consuming and Expensive.

Submitting different and Huge (Lorry-sized) applications due to which a NDA were considered as "Nightmare".

This led to:

1. Rising costs of health care.

2. Escalation of the cost of Research and Development.

Hence, need to meet the public expectation that there should be a minimum of delay in making safe and efficacious new treatments available to patients have arisen.

"Hence, there was an urgent need to rationalize and harmonize regulation." (1)

\section{HISTORY}

EU took initiative of harmonization of regulatory requirements in 1980.

At the same time, bilateral discussions between Europe, Japan and US on possibilities for Harmonization at WHO Conference of Drug Regulatory authorities, in Paris, in 1989, specific plans for action began to materialize.

Authorities approached IFPMA (International Federation of Pharmaceutical Manufacturers and Associations) to discuss joint regulatoryindustry initiative on international harmonization and ICH was conceived.
The birth of $\mathrm{ICH}$ took place at a meeting in April 1990, hosted by the EFPIA (European Federation of Pharmaceutical Industries and Association) in Brussels. (1)

\section{ICHs decades}

\section{As the $\mathbf{1}^{\text {st }}$ decade}

Significant progress in the development of Tripartite ICH Guidelines on Safety, Quality and Efficacy topics

Work has also undertaken on number of important multidisciplinary topics-

MedDRA (Medical Dictionary of Regulatory Activities)

CTD (Common Technical Document)

\section{As the $2^{\text {nd }}$ decade}

The development of ICH guidelines continued, but with more attention given to the following need of:

Maintain already existing Guidelines as Science and Technology continued to evolve;

Expand communication and dissemination of information on ICH Guidelines.

\section{As the $3^{\text {rd }}$ decade}

ICHs attention is directed towards extending the benefits of harmonization beyond the $\mathrm{ICH}$ regions. (1)

\section{ORGANIZATION OF ICH}

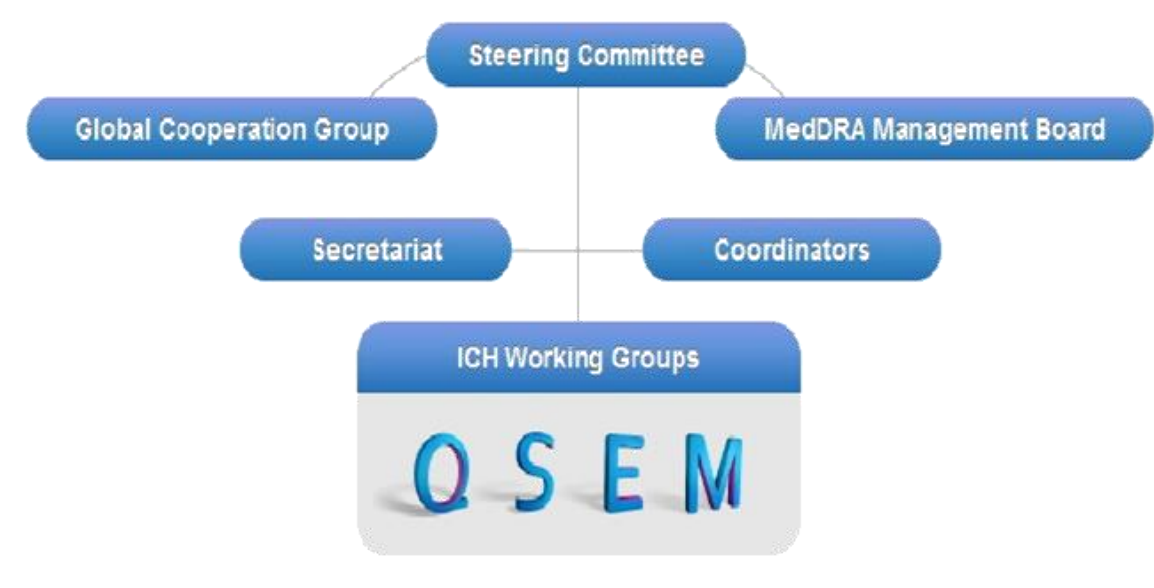

Figure 1: Organization of ICH 


\section{Goals of ICH}

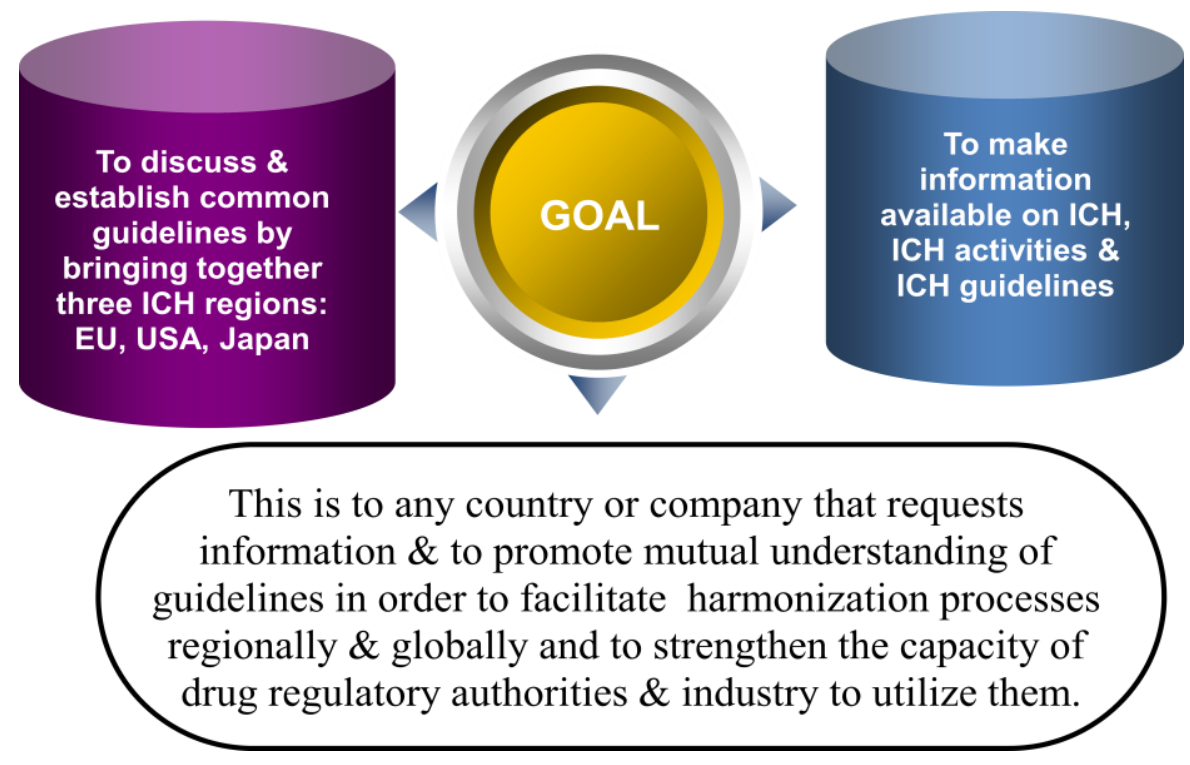

Figure 2: Goals of ICH

\section{Purpose of ICH}

\section{The basic purpose of ICH are-}

* To monitor, update and increase the international harmonization of Technical Requirements.

* To ensure Safety, Efficacy and Quality of medicines that must be developed and registered in the most efficient and cost effective manner.

\section{Quality Topics}

Table 1: Quality Topics

\begin{tabular}{|l|l|}
\hline Q1 & STABILITY \\
\hline Q2 & ANALYTICAL VALIDATION \\
\hline Q3 & IMPURITES \\
\hline Q4 & PHARMACOPOEIAS \\
\hline Q5 & $\begin{array}{l}\text { QUALITY OF BIOTECHNOLOGICAL } \\
\text { PRODUCTS }\end{array}$ \\
\hline Q6 & SPECIFICATIONS \\
\hline Q7 & GMPS \\
\hline Q8 & PHARMA. DEVELPOMENT \\
\hline Q9 & QRM \\
\hline Q10 & PHARMA. QUALITY SYSTEM \\
\hline
\end{tabular}

To promote and protect public health from an international perspective.

* To prevent unnecessary duplication of clinical trials in humans.

* To minimize the use of animal testing without compromising the safety and effectiveness.

* To improve the efficiency of Global Drug Development. (1) 


\section{ICH GUIDELINES}

\section{'Q'-Quality Topics \\ i.e. those related to Chemical \& \\ Pharmaceutical Quality Assurance.}

\section{'S'-Safety Topics}

i.e. those related to In-Vitro \& In-vivo pre-clinical studies.

\section{'E'- Efficacy Topics}

i.e. those related to clinical studies in

Human Subject.

\section{'M'- Multidisciplinary Topics}

i.e. cross-cutting topics which do not fit uniquely into one of the above categories.

Figure 3: ICH Guidelines

\section{Q9- QUALITY RISK MANAGEMENT}

\section{Definition}

Quality: Degree to which a set of inherent properties of a product, system or process fulfills requirements.

\section{MANAGEMENT}

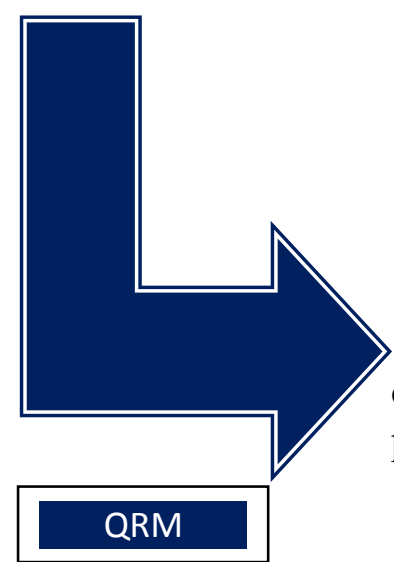

Systematic process for the assessment, control, rommunication and review of risks to the quality of the drug (medicinal) product across the product lifecycle.

Figure 4: QRM Management

\section{PRINCIPLES OF QUALITY RISK MANAGEMENT}

Two primary principles of quality risk management are:
Risk: Combination of the probability of occurrence of harm and the severity of that harm. 
- The level of effort, formality, and documentation of the quality risk management process should be commensurate with the level of risk.

\section{SCOPE OF QRM}

This guidance provides principles and examples of tools for quality risk management that can be applied to different aspects of pharmaceutical quality. These aspects include development, manufacturing, distribution, inspection, and submission/review processes throughout the lifecycle of drug substances, drug products, biological and biotechnological products (including the use of raw materials, solvents, excipients, packaging and labelling materials in drug products, biological and biotechnological products).

\section{PROCESS OF QRM(2)}

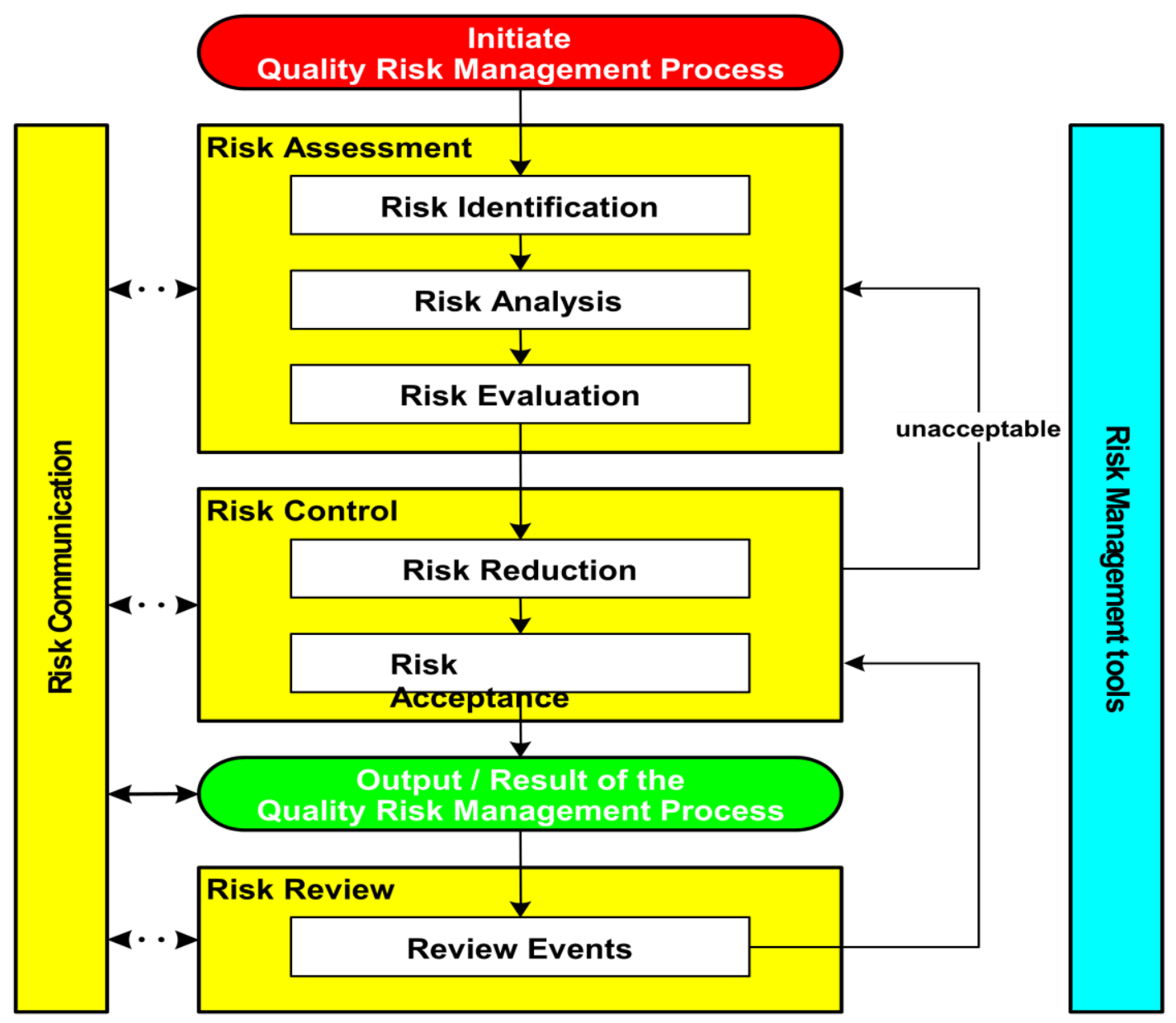

Figure 5: Process of QRM

\section{RISK MANAGEMENT METHODS AND TOOLS (2)}

\section{Basic Risk Management Facilitation Methods}

Some of the simple techniques that are commonly used to structure risk management by organizing data and facilitating decision making are:

\section{Failure Mode Effects Analysis (FMEA)}

FMEA provides for an evaluation of potential failure modes for processes and their likely effect on outcomes and/or product performance. (3)

\section{Potential Areas of Use}

FMEA can be used to prioritize risks and monitor the effectiveness of risk control activities. 


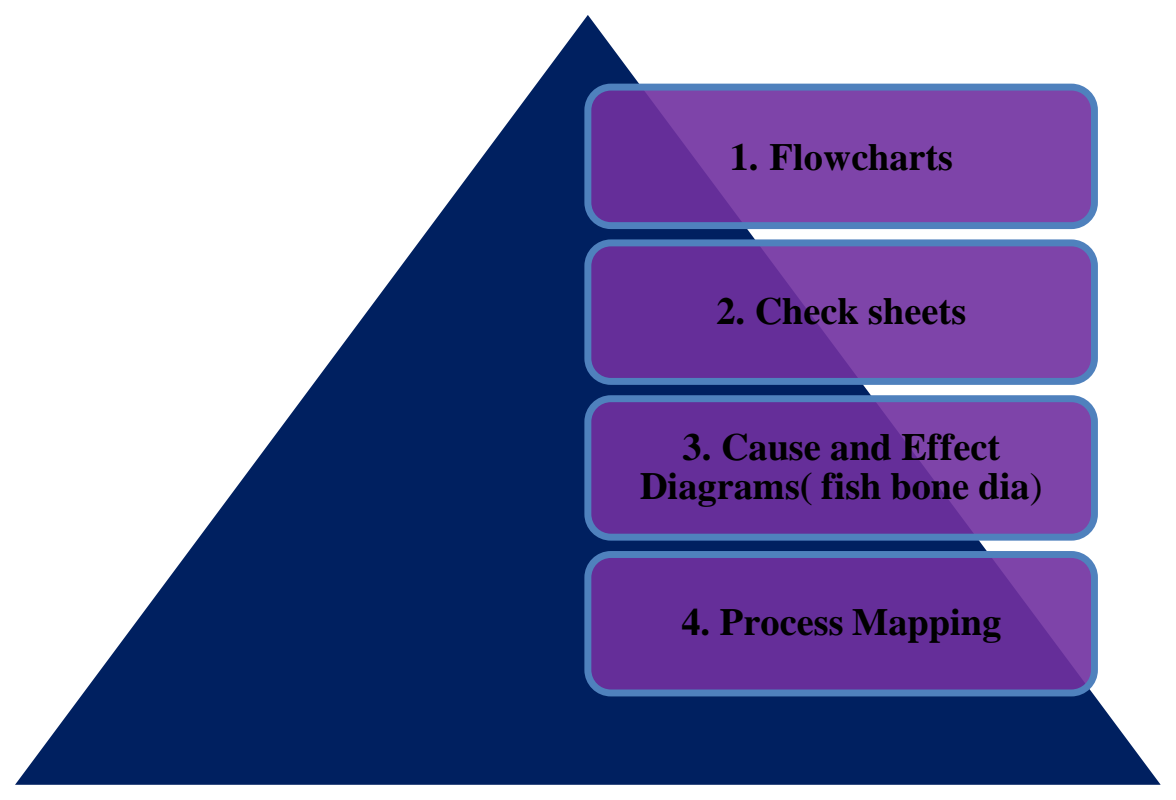

Figure 6: Risk Management methods and Tools

\section{Failure Mode, Effects and Criticality Analysis (FMECA)}

FMEA might be extended to incorporate an investigation of the degree of severity of the consequences, their respective probabilities of occurrence, and their detectability, thereby becoming a Failure Mode, Effects, and Criticality Analysis (FMECA). (4)

\section{Potential Areas of Use}

FMECA application in the pharmaceutical industry should mostly be utilized for failures and risks associated with manufacturing processes.

\section{Fault Tree Analysis (FTA)}

The FTA tool is an approach that assumes failure of the functionality of a product or process. This tool evaluates system (or subsystem) failures one at a time but can combine multiple causes of failure by identifying causal chains. (5)

\section{Potential Areas of Use}

FTA can be used to investigate complaints or deviations in order to fully understand their root cause and to ensure that intended improvements will fully resolve the issue and not lead to other issues (i.e. solve one problem yet cause a different problem). Fault Tree Analysis is an effective tool for evaluating how multiple factors affect a given issue.

\section{Hazard Analysis and Critical Control Points (HACCP)}

It is a structured approach that applies technical and scientific principles to analyze, evaluate, prevent, and control the risk or adverse consequence(s) of hazard(s) due to the design, development, production, and use of products. (6)

\section{Hazard Operability Analysis (HAZOP)}

HAZOP is based on the assumptions that risk events are caused by deviations from the design or operating intentions. It is a systematic brainstorming technique for identifying hazards.

\section{Preliminary Hazard Analysis (PHA)}

PHA is a tool of analysis based on applying prior experience or knowledge of a hazard or failure to identify future hazards, hazardous situations and events that might cause harm, as well as to estimate their probability of occurrence for a given activity, facility, product, or system. 


\section{Risk Ranking and Filtering}

Risk ranking and filtering is a tool for comparing and ranking risks. Risk ranking of complex systems typically involves evaluation of multiple diverse quantitative and qualitative factors for each risk. "Filters," in the form of weighting factors or cut-offs for risk scores, can be used to scale or fit the risk ranking to management or policy objectives.

\section{Supporting Statistical Tools}

They can enable effective data assessment, aid in determining the significance of the data set(s), and facilitate more reliable decision making.

\section{IMPLEMENTATION OF QRM}

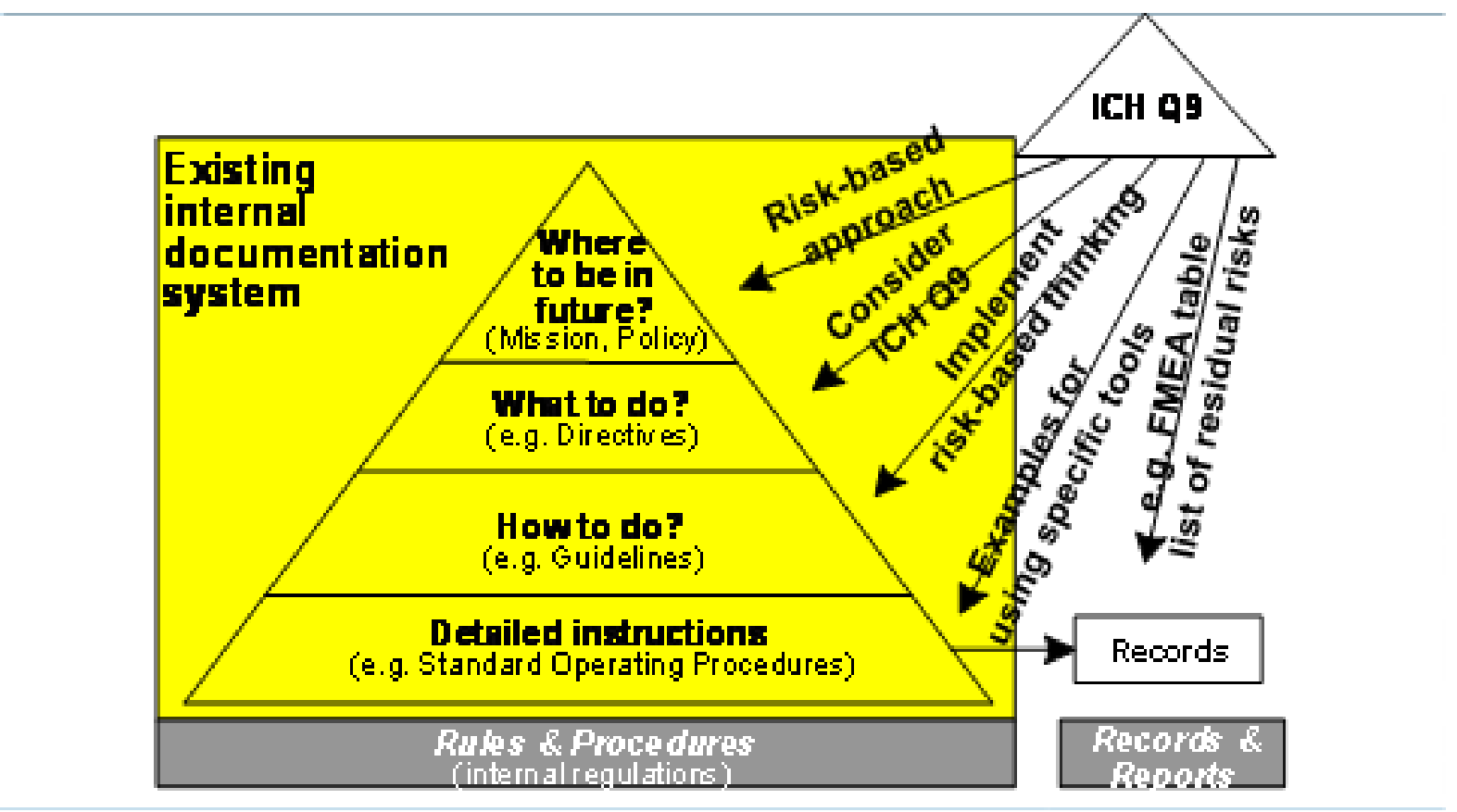

Figure 7: Implementation of QRM

\section{HURDLES IN ABSENCE OF QRM}

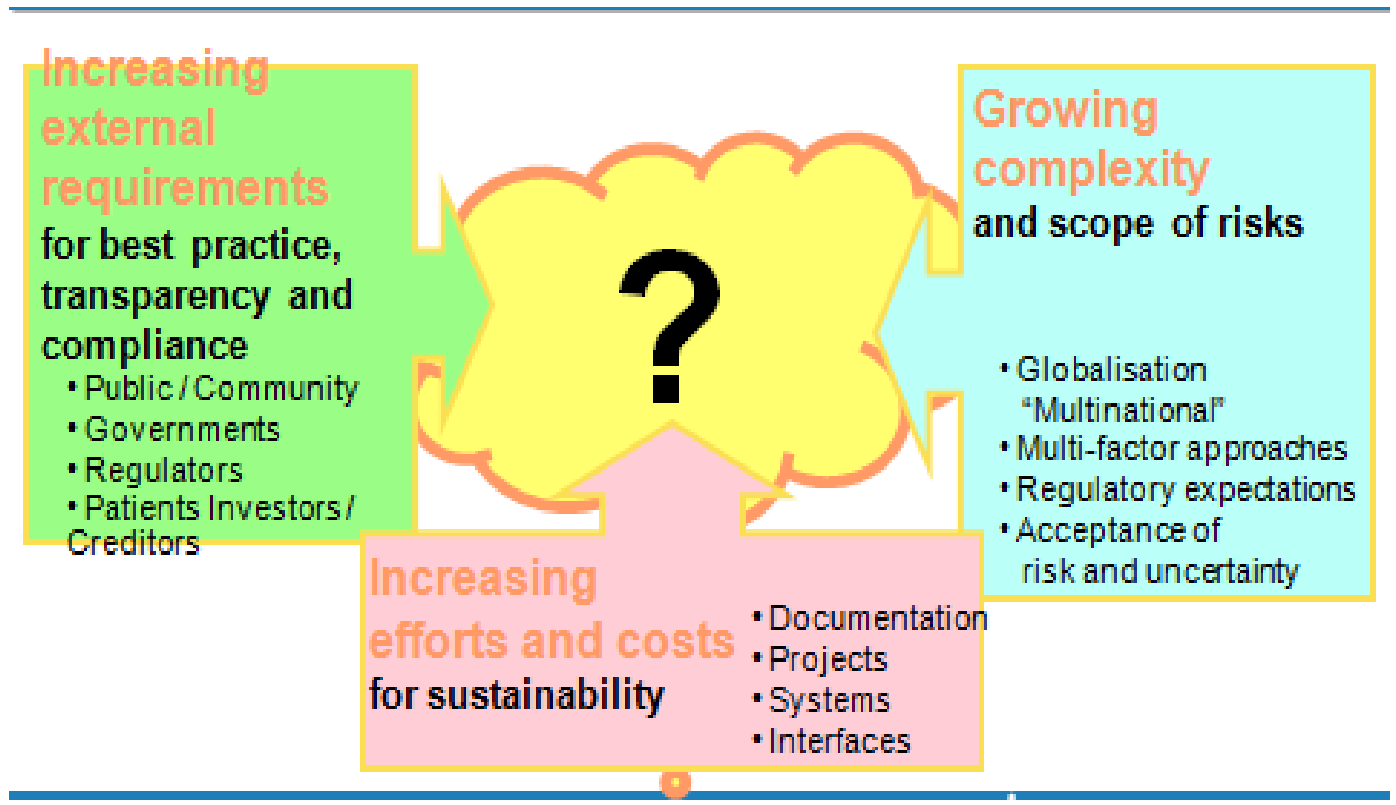

Figure 8: Hurdles in absence of QRM 
The absence of a harmonised risk management approach has the following impacts on the patient, regulator and/or industry:

- Product may not be available to patients, when needed.

- May increase the potential for the release of unacceptable product to the market

- New product introductions to the marketplace may be delayed.

- Delays may occur during implementation of changes and improvements to processes.

- Safe and effective drugs may be discarded or recalled from the market.

- Manufacturers may be reluctant to implement new technologies or continuous improvements to the products or processes.

- Scarce resources may not be optimally allocated.

- Lack of appropriate data to evaluate risk most effectively

\section{Issues to be Resolved}

The following issues need to be resolved:

- Terminology including a definition of quality, risk, risk management, etc

- Principles for how risk management should be effectively applied and consistently integrated into decisions regarding product quality and impact on the patient.

- Identifying circumstances when applying risk management principles is not feasible or appropriate.

- Defining what principles of risk management apply to the industry, to the regulators, and to both, throughout the product lifecycle.

- How, what and when information is exchanged between and within industry and regulators, in a global context.

- How to ensure synergy with the Pharmaceutical Development EWG and the resulting guidelines.

- Defining roles and responsibilities of regulators and industry, including communication responsibilities.
- How risk can be incorporated into resource allocation decisions.

\section{BENEFITS}

Benefits of the harmonized risk management guideline to all ICH parties and observers:

- Enhanced patient confidence in decision making on pharmaceutical quality

- Promotes more effective use of regulatory agency and industry resources

- Establishes a systematic, well-informed and thorough method of decision making which leads to greater transparency and predictability

- Increased knowledge of exposure to risk

- Fosters quality by design, continuous improvement and new technology introduction, which generally leads to enhanced product quality

- Enhanced empowerment and flexibility in work.

\section{POTENTIAL APPLICATIONS FOR QUALITY RISK MANAGEMENT (2)}

1. Quality Risk Management as Part of Integrated Quality Management

\section{Documentation}

- To review current interpretations and application of regulatory expectations.

- To determine the desirability of and/or develop the content for SOPs, guidance, etc.

\section{Training and education}

- To determine the appropriateness of initial and/or ongoing training sessions based on education, experience, and working habits of staff, as well as on a periodic assessment of previous training (e.g., its effectiveness).

- To identify the training, experience, qualifications, and physical abilities that allow personnel to perform an operation reliably and with no adverse impact on the quality of the product. 


\section{Quality defects}

- To provide the basis for identifying, evaluating, and communicating the potential quality impact of a suspected quality defect, complaint, trend, deviation, investigation, out of specification result, etc.
To facilitate risk communications and determine appropriate action to address significant product defects, in conjunction with regulatory authorities (e.g., recall).

\section{Empowerment \& Flexibility}

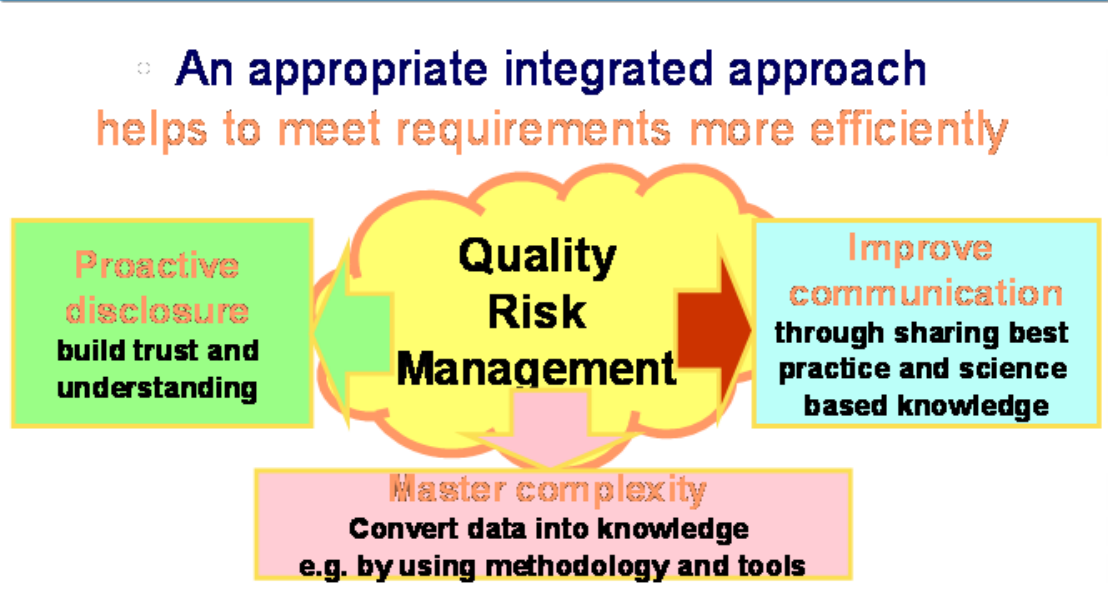

Figure 9: Benefits of the harmonized risk management guideline

\section{Auditing/Inspection}

To define the frequency and scope of audits, both internal and external, taking into account factors such as:

- Existing legal requirements,

- Overall compliance status and history of the company or facility.

- Robustness of a company's quality risk management activities etc.

\section{Periodic review}

- To select, evaluate, and interpret trend results of data within the product quality review.

- To interpret monitoring data (e.g., to support an assessment of the appropriateness of revalidation or changes in sampling).

\section{Change management/change control}

- To manage changes based on knowledge and information accumulated in pharmaceutical development and during manufacturing.
- To evaluate the impact of the changes on the availability of the final product.

- To evaluate the impact on product quality of changes to the facility, equipment, material, manufacturing process, or technical transfers.

- To determine appropriate actions preceding the implementation of a change, e.g., additional testing, (re)qualification, (re)validation, or communication with regulators.

2. Quality Risk Management as Part of Regulatory Operations

\section{Inspection and assessment activities}

- To assist with resource allocation including, for example, inspection planning and frequency, and inspection and assessment intensity.

- To evaluate the significance of, for example, quality defects, potential recalls, and inspectional findings.

- To determine the appropriateness and type of post inspection regulatory follow-up. 
- To evaluate information submitted by industry, including pharmaceutical development information.

- To evaluate impact of proposed variations or changes.
- To identify risks that should be communicated between inspectors and assessors to facilitate better understanding of how risks can be or are controlled (e.g., parametric release, Process Analytical Technology (PAT).

\section{What happens to regulatory expectations when things go wrong?}

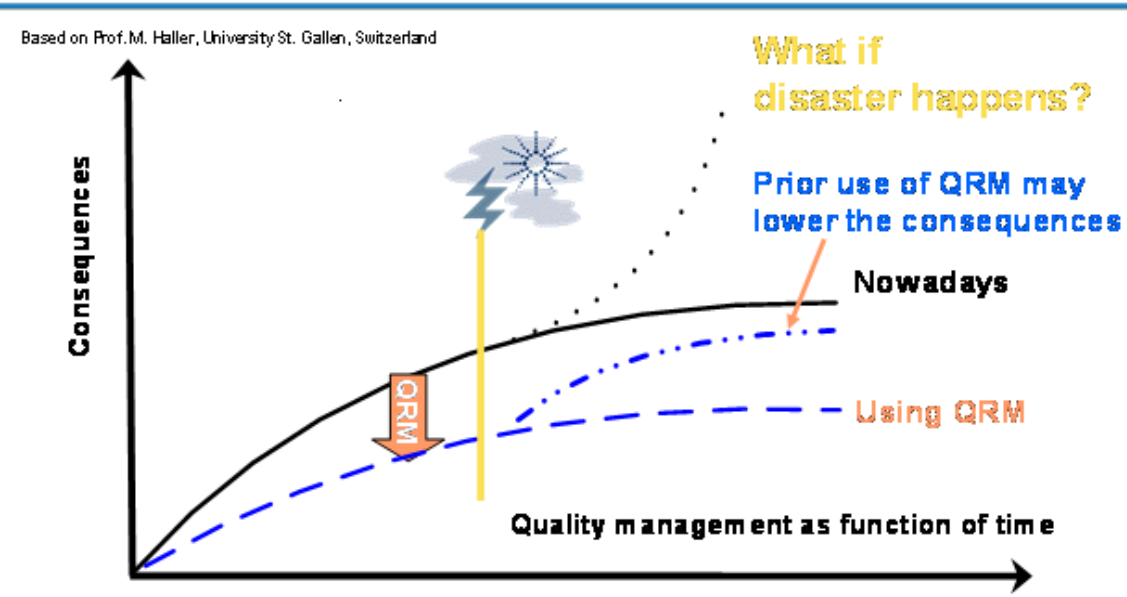

Figure 10: Quality Risk Management as part of Regulatory Operations

3. Quality Risk Management as Part of Materials Management

Assessment and evaluation of suppliers and contract manufacturers

- To provide a comprehensive evaluation of suppliers and contract manufacturers (e.g., auditing, supplier quality agreements)

\section{Starting material}

- To assess differences and possible quality risks associated with variability in starting materials (e.g., age, route of synthesis).

\section{Use of materials}

- To determine whether it is appropriate to use material under quarantine (e.g., for further internal processing).

- To determine appropriateness of reprocessing, reworking, use of returned goods.
Storage, logistics and distribution conditions

- To assess the adequacy of arrangements to ensure maintenance of appropriate storage and transport conditions (e.g., temperature, humidity, container design).

- To determine the effect on product quality of discrepancies in storage or transport conditions(e.g., cold chain management) in conjunction with other ICH guidance.

- To maintain infrastructure (e.g., capacity to ensure proper shipping conditions, interim storage, handling of hazardous materials and controlled substances, customs clearance).

- To provide information for ensuring the availability of pharmaceuticals (e.g., ranking risks to the supply chain).

\section{Quality Risk Management as Part of} Production Validation 
- To identify the scope and extent of verification, qualification, and validation activities (e.g. analytical methods, processes, equipment, and cleaning methods).

- To determine the extent for followup activities (e.g., sampling, monitoring, and re-validation).

- To distinguish between critical and noncritical process steps to facilitate design of a validation study. (7)

In-process sampling and testing
- To evaluate the frequency and extent of in-process control testing (e.g., to justify reduced testing under conditions of proven control).

- To evaluate and justify the use of process analytical technologies (PAT) in conjunction with parametric and real time release.

\section{Production planning}

- To determine appropriate production planning (e.g., dedicated, campaign, and concurrent production process sequences).

\section{Managing the risk of drug product use}

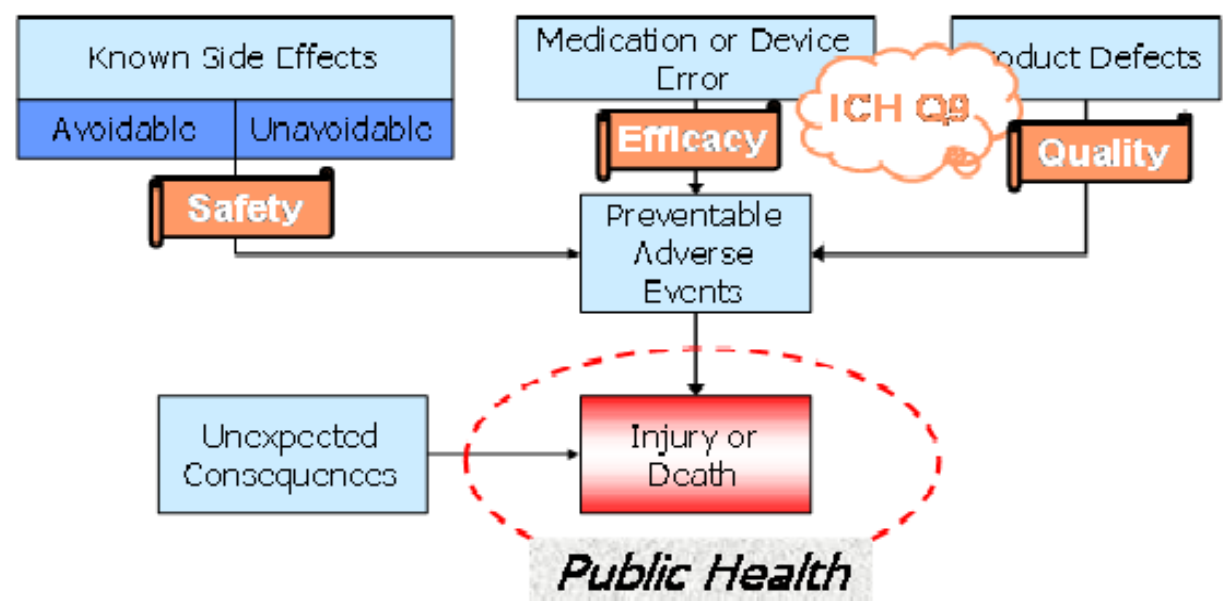

Figure 11: Managing risk of Drug Product use

5. Quality Risk Management as Part of Laboratory Control and Stability Studies

\section{Out of specification results}

- To identify potential root causes and corrective actions during the investigation of out of specification results. $(8,9)$

\section{Retest period/expiration date}

- To evaluate adequacy of storage and testing of intermediates, excipients, and starting materials.
6. Quality Risk Management as Part of Packaging and Labelling

\section{Design of packages}

- To design the secondary package for the protection of primary packaged product (e.g., to ensure product authenticity, label legibility).

Selection of container closure system

- To determine the critical parameters of the container closure system.

\section{Label controls}

- To design label control procedures based on the potential for mix-ups involving different product labels, 
including different versions of the same label.

\section{CONCLUSION}

1. Over all Positive Contribution is towards patient protection

- Further develops Quality Risk Management awareness that is already part of industry and regulatory culture.

2. Ongoing change in behaviour

- Identifying risks can be positive

- A long list of identified risks that are assessed and controlled provides high quality capability

- Awareness of quality risks

- "Risk-based approach"

- A potential of risks remains - No "Zero" risk!

\section{ACKNOWLEDMENT}

This is matter of great pride to pursue my Master of Pharmacy from Delhi Institute of Pharmaceutical Sciences and Research (DIPSAR).

I would like to express my sincere gratitude to my guide Dr. Ramesh B. Bodla, (Associate Professor), who gave me the appropriate guidance and has shown interest and encouraged me to carry out work on this review article.

I would also like to express thanks to Dr. D. P. Pathak (Director, DIPSAR) for granting me the opportunity to undertake this article on " $\mathrm{ICH}$ : Quality System Management".

I would like to express my gratitude and thanks to Shweta Singh for her continuous support and encouragement and for being a helping hand during this article work.

\section{CONFLICT OF INTEREST}

Author declares that there are no conflict of interest.

\section{REFERENCES}

1. Mario Chen. Brief Introduction to the $\mathrm{ICH}$ Guidelines. Family Health International Biostatistics Workshop [Internet].India; 2007 March [cited 2014 July 15]. Available from:
www.icssc.org/Presentations/NewDelhi2007/3BriefIn trototheICHGuidelinesIndia2007.pdf

2. Guidance for Industry-Center for Drug Evaluation and Research. [Internet] Fishers Lane, Rockville: FDA; 2006 June [cited 2014 June 02]. Available from: http://www.fda.gov/cder/guidance/index.htm

3. Stamatis D H. FMEA from Theory to Execution, 2nd ed. ASQ Quality Press; 2003. p.391-400, ISBN 0873895983.

4. Roberts P. FMECA [Internet].UK: FMECA; 2007 Jan [cited 2014 July 2]. Available from: www2.warwick.ac.uk/fec/sci/wmg/ftmsc/modules/mo dulelist/peuss/slides/section_12a_fmeca_notes.pdf.

5. FTA - Fault tree analysis, $2^{\text {nd }}$ ed. IEC 61025 [Internet]. 2006 [cited 2014 July 7]. Available from: webstore.iec.ch/preview/info_iec61025\%7Bed2.0\%7 Den_d.pdf.

6. Methodology to pharmaceuticals, Annex-7: Application of Hazard Analysis and Critical Control Point (HACCP). WHO Technical Report. S. No. 908; 2003.

7. Safety aspects - Guideline for their inclusion in standards-2014, no. 51-ISO/IEC Guide [Internet]. 2014 [cited 2014 July 27]. Available from: www.iso.org/obp/ui/\#iso:std:iso-iec:guide:51:ed3:v1:en.

8. Thrussell IR. Quality Risk Management and its application in sterile processing. WHO [Internet]. WHO; 2009 Nov [cited 2014 July 11]. Available from:

apps.who.int/prequal/training resources/3-3_Risk_ Management.ppt

9. Risk management - Vocabulary - Guidelines for use in standards-2009, no.73-ISO/IEC Guide. [Internet]. ISO; 2009 [cited 2014 July 27]. Available from: www.iso.org/obp/ui/\#iso:std:iso:guide:73:ed-1:v1:en. 